PontIFícIA UNIVERSIDADE CATÓLICA dO RIO DE JANEIRO

\title{
Marketing Sensorial e a Realidade Virtual Como Estratégia de Marketing para o Mercado de Turismo
}

Rafael Campos Asvolinsque

Trabalho de Conclusão de Curso

Centro de ciências socials - CCS

Departamento de AdMinistraÇÃo

Graduação em Administração de Empresas 
Rafael Campos Asvolinsque

\section{Marketing Sensorial e a Realidade Virtual Como Estratégia de Marketing para o Mercado de Turismo}

Trabalho de Conclusão de Curso

Trabalho de Conclusão de Curso, apresentado ao programa de graduação em Administração da PUC-Rio como requisito parcial para a obtenção do titulo de graduação em Administração.

Orientador(a) : Marina Frid 
"Pois, que adianta ao homem ganhar o mundo inteiro e perder a sua alma?" Jesus Cristo 


\section{Agradecimentos}

Como tudo isso aconteceria se portas não fossem abertas? Se o impossível não se tornasse possível? Por isso meu coração se enche de gratidão para com Deus, que é o único capaz de tais feitos. Como se não fosse suficiente, me dá presentes em forma de pessoas que espelham todo o amor e cuidado que Ele tem por mim, para que nos dias difíceis eu jamais me esqueça de que Ele está comigo e que Ele não falha.

Uma escolha que não pude fazer e que suas consequências me fazem ser grato a cada manhã, essa é a minha família. Cooperaram para a construção da minha personalidade e caráter com demonstrações diárias do que é dar a vida por alguém, assim como o nosso Senhor nos ensinou. Tenho certeza que se eu tivesse que escolher, não teria sido tão feliz. Eber, Nancy, Raquel, Thiago e Pipa (não podia faltar), vocês são a maior referência do amor de Deus por mim e são exemplos de vida com Deus que tento me tornar mais parecido a cada dia.

Uma oração que eu faço todos os dias é a de que eu viva a vontade de Deus para minha vida, pois a palavra de Deus diz que essa vontade é boa, perfeita e agradável. A vontade d’Ele trouxe pessoas que admiro como verdadeiros heróis. Que arrancam sorrisos do meu rosto e colhem cada lágrima sempre que necessário. Pablo, Marlon, Felipe, Natasha, Fabio, Márcia, Alessandro e Toni Luidgi, foram dias difíceis durante a graduação, mas vocês me faziam enxergar que os planos e os sonhos de Deus eram realmente maiores do que eu podia imaginar.

Nada feito durante o curso da graduação teria sido válido se o degrau do trabalho de conclusão de curso não fosse alcançado, por isso um obrigado muito especial à professora Marina Frid e a todos os que disponibilizaram tempo e esforços para me ajudar com este artigo. Com certeza a colheita do que vocês têm semeado será excelente. 


\section{Resumo}

Asvolinsque, Rafael Campos. Marketing Sensorial e a Realidade Virtual Como Estratégia de Marketing para o Mercado de Turismo. Rio de Janeiro, 2017. 27p. Trabalho de Conclusão de Curso - Departamento de Administração. Pontifícia Universidade Católica do Rio de Janeiro.

Este estudo tem como principal objetivo encontrar oportunidades para empresas de tecnologia, produtoras de softwares de realidade virtual, no mercado de turismo, trabalhando com ações de marketing sensorial através da tecnologia. Tendo em vista o pouco conhecimento da tecnologia por parte da população e as dificuldades de acesso a essa tecnologia, para explorar os efeitos que são causados nos clientes em potencial nesse tipo de ação. Sendo realizadas entrevistas com profissionais do mercado e com usuários do aplicativo desenvolvido por esses profissionais, que também se encaixam no perfil de consumidores em potencial do mercado de turismo. Com as respostas de ambos os grupos é possível traçar metas mais tangíveis para novas pesquisas conclusivas num futuro próximo.

Palavras-chave: Realidade Virtual, marketing sensorial, turismo. 


\section{Abstract}

Asvolinsque, Rafael Campos. Sensory Marketing and Virtual Reality as a Strategy for Tourism Market. Rio de Janeiro, 2017. 27p. Undergraduate Thesis - Business Department. Pontifical Catholic University of Rio de Janeiro.

This article has as its main objective to find opportunities at the tourism market for technology companies and producers of virtual reality software, through the sensory marketing strategy in partnership with this kind of technology. Keeping in mind the low level of knowledgement of Rio de Janeiro people and the hard access to this technology in Rio de Janeiro, exploring the effects caused on the clients of this marketing strategy. Interviews were made with the technology market professionals and with the consumers of the app developed by them, which can be classified as tourism market potential clients. With both groups answers we are able to create new targets for new conclusive researches in a close future.

Key-words

Virtual reality, sensory marketing, tourism market. 


\section{Sumário}

1 Introdução 1

1.1. Problema 1

1.2. Objetivo do estudo 2

1.3. Delimitação do estudo 2

1.4. Relevância do Estudo 3

2 Contexto e Realidade Investigada 4

2.1. Organizações 4

2.2. Realidade Virtual 5

2.3. Aplicativo Localidades Antigas 5

2.4. Realidade Virtual e Marketing Sensorial 6

$\begin{array}{ll}\text { 2.5. Turismo } & 7\end{array}$

3 Fundamentação Teórica 8

3.1. Marketing Sensorial 8

3.2. Turismo 9

3.3. Realidade Virtual 9

4 Metodologia de Pesquisa 12

4.1. Escolha e Apresentação do Método 12

4.2. Tipos de Pesquisa 13

4.3. Relevância do Questionário e das Entrevistas 15

$\begin{array}{ll}\text { 4.4. Delimitações do Estudo } & 15\end{array}$

5 Apresentação e Análise dos Resultados $\quad 17$

$\begin{array}{ll}\text { 5.1. Entrevistas } & 17\end{array}$

5.2. Descrição do perfil de usuários entrevistados 21

5.3. Análise dos Resultados 22

$\begin{array}{ll}6 \text { Conclusões } & 26\end{array}$ 
7 Referências Bibliográficas

Anexo 1 - Perguntas das Entrevistas com os empresários

Anexo 2 - Questionário para consumidores 
Lista de Tabelas

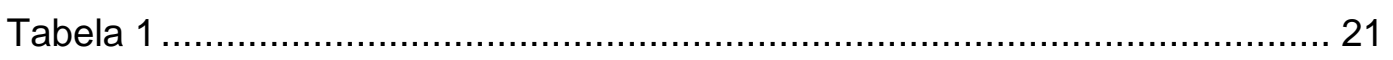




\section{Lista de Figuras}

Figura 1: Exemplo de uso dos óculos junto com o celular para RV .................... 7

Figura 2: Exemplo de ambiente de imersão virtual inspirado em Game of

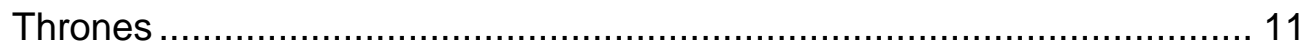

Figura 3: Google Cardboard. Exemplo de Óculos para RV ............................ 20 


\section{Introdução}

\subsection{Problema}

Inovações tecnológicas, especialmente aquelas relativas à comunicação, oferecem sempre novas possibilidades para as estratégias de marketing. Podemos exemplificar isso através de aplicativos utilizados por grandes marcas como a Netshoes, onde o consumidor pode realizar suas compras ou receber avisos de promoções na tela do seu celular. Porém, devido a velocidade das mudanças, principalmente na área tecnológica, nem sempre são levantados os impactos das interações entre as tecnologias e as estratégias de marketing sobre os consumidores.

A recente tecnologia lançada, que tem ganhado espaço no nosso dia a dia, é a realidade virtual $(\mathrm{RV})$. Esse conceito tecnológico está vinculado principalmente à utilização do sentido da visão para ter a experiência de ser "transportado" para essa realidade digital. Em paralelo, a estratégia do marketing sensorial ganha espaço no mercado brasileiro. Além de potencializar a relação entre marcas e clientes por meio de associações táteis, visuais, auditivas e olfativas, o marketing sensorial também acaba por criar novos produtos. Por exemplo, as fragrâncias das lojas M Martan e Alfaias são vendidas para que seus clientes coloquem o mesmo cheiro das lojas em suas casas. Outros exemplos são aplicativos de turismo que aumentam as experiências vividas no local visitado pelos turistas.

Como exemplo de integração das duas áreas, tecnologia e marketing, o presente trabalho busca, através da análise da utilização por parte de turistas ou aficionados por tecnologia, encontrar oportunidades de integração das duas áreas com fim de obter retorno financeiro e vantagem competitiva no mercado de turismo carioca. Ou seja, enxergar se clientes de agências de viagens, de hotéis e todos os outros tipos de serviços e produtos voltados para o mercado de turismo encontram valor no uso da RV voltada para esse mesmo mercado, criando aumento do seu consumo, relacionamento e propaganda das marcas e empresas que disponibilizarem os mesmos. Sendo assim, cria-se por natureza, oportunidade para empresas produtoras de softwares de RV no mercado de turismo do Rio de Janeiro. 


\subsection{Objetivo do estudo}

O objetivo deste estudo é analisar oportunidades de mercado para empresas produtoras de softwares de RV em ações de marketing produzidas por empresas de serviços e produtos voltados para o setor de turismo. Para tanto, o trabalho investiga os projetos desenvolvidos pela OverReal, desenvolvedora de software de RV, em parceria com o seu cliente requisitante de produto XPTO, produtora de conteúdo audiovisual do Rio de Janeiro. O nome fictício foi adotado neste estudo para preservar o anonimato da empresa, que não liberou a divulgação da sua marca.

As informações do trabalho podem cooperar para o desenvolvimento de ferramentas mais aptas para influenciar o público alvo, gerando melhores experiências e aumentando o valor agregado de produtos oferecidos no mercado, através da tecnologia e da estratégia mercadológica estudada. Além de identificar padrões de comportamento, pontos que agradam e desagradam os consumidores do material virtual utilizado no mercado sensorial do Rio de Janeiro.

\subsection{Delimitação do estudo}

Este artigo discorre acerca da utilização do conceito tecnológico da Realidade Virtual a partir da estratégia de marketing sensorial utilizada pela empresa OverReal, junto a XPTO no setor de turismo. O projeto do aplicativo Localidades Antigas teve início no mês de Agosto de 2016 e dura até os dias de hoje, tendo em vista que os aplicativos gerados através do mesmo ainda estão disponíveis nas lojas virtuais para a aquisição dos clientes. Sendo assim, este artigo irá desenvolver a análise do impacto do aplicativo Localidades Antigas sobre os seus consumidores como forma de identificar o potencial das ações que podem ser desenvolvidas pelas empresas produtoras de material tecnológico no setor de turismo.

Os dados descritos durante todo o trabalho foram obtidos através da empresa OverReal. Teremos como delimitações o uso e disponibilidade das ferramentas e tecnologias referentes à realidade virtual no Rio de janeiro e seu impacto no mercado de turismo local. 


\subsection{Relevância do Estudo}

Além da utilização para o desenvolvimento do empreendimento pessoal pertencente ao setor tecnológico, servindo como material para produção de softwares com mais qualidade e argumentos para conquistar novos clientes, o estudo se torna relevante para empresas que estejam incluídas no mesmo setor e que se interessam por desenvolver formas de comunicação mais eficientes com seus consumidores ou elementos chave.

Outro fator de grande relevância é a busca por encontrar novos métodos de atratividade para o mercado de turismo através da utilização das tecnologias em estudo. Estudo de mercado, tanto tecnológico, quanto de turismo e técnicas aplicadas de administração através do marketing, fora desenvolvimento das tecnologias com uma visão mais focada nos seus clientes em potencial são de grande potencial para academia brasileira. 


\section{Contexto e Realidade Investigada}

\subsection{Organizações}

A OverReal se trata de uma empresa criada em março de 2017 por Marlon Braga, profissional da área de computação, recém-formado pela UERJ. Buscando realizar seu sonho de desenvolver um negócio próprio e evoluir profissionalmente e financeiramente, seu objetivo era empregar os conhecimentos adquiridos durante a sua graduação ao produzir softwares voltados à realidade virtual e aumentada para seus clientes. Levando em consideração a recente criação da empresa, devemos considerar para os devidos fins do artigo que projetos como o da produção do aplicativo Localidades Antigas, que foi desenvolvido antes da criação da empresa, quando Marlon ainda trabalhava como freelance, são também tratados como pertencentes a companhia.

Ao identificar a oportunidade no mercado tecnológico do Rio de Janeiro, a OverReal decide focar no desenvolvimento de softwares voltados para as realidades virtual e aumentada, tendo em vista que no Brasil, mais precisamente no Rio de Janeiro, o mercado ainda apresenta como principais oportunidades a facilidade para se obter destaque, devido à pouca concorrência, e oportunidades de atuação em diferentes setores, como de turismo, que será analisado através deste artigo, de construção e imobiliário, além de lançamentos e eventos voltados para a promoção e marketing de empresas ou marcas dos mais diversos, como aconteceu na casa da NBA durante as Olímpiadas do Rio de Janeiro, no qual foi disponibilizado um ambiente de imersão virtual onde o usuário passava pela experiência de estar dentro de um jogo de basquete. $\mathrm{Na}$ casa da $N B A$, os visitantes utilizavam os óculos de RV com fones de ouvido específicos e subiam em plataformas que possuíam um piso que vibrava conforme os movimentos que aconteciam no ambiente simulado.

A outra organização envolvida no projeto a ser descrito neste trabalho é a XPTO, empresa que trabalha no mercado de produção de conteúdo audiovisual e de projetos interativos, com diversos prêmios tanto no âmbito nacional quanto internacional. Seu fundador, aqui chamado pelo nome fictício José da Silva, que também possui premiações como a do Young Creative Entrepreneur Award, teve 
como um de seus maiores projetos o aplicativo Localidades Antigas, que busca reconstruir ambientes de diferentes cidades em realidade virtual, mostrando como era o local antes e depois de uma obra de restauração. Como exemplo, temos o projeto que será tratado durante este artigo, que revelava as diferenças estruturais entre a Praça Mauá antes e depois de sua revitalização conduzida pela prefeitura do Rio de Janeiro no período de 2007 a 2016.

\subsection{Realidade Virtual}

Nos dias de hoje, diversas são as ferramentas tecnológicas voltadas para o entretenimento. Novas mídias e tecnologias que buscam suprir o desejo de se viver algo que vá além do natural, que expanda a nossa imaginação. Sendo assim, desenvolve-se a realidade virtual que busca, literalmente, expandir os limites das experiências de seus usuários. Por meio da RV os usuários têm sensações que não são permitidas ou alcançadas no nosso ambiente natural, como por exemplo, brincar numa montanha russa, assistir um filme como se estivesse num cinema ou surfar a onda dos sonhos, já que tudo isso pode acontecer, sem que você saia do seu sofá.

Um grande exemplo é a utilização no ramo de treinamento para medicina. Os treinamentos passam a ser realizados através da realidade virtual em corpos digitais, com instrumentos digitais, o que diminui riscos, custos, facilita operacionalização, otimiza tempo e esforços, sem perder o contato com atributos reais. Pelo contrário, a simulação pode ser ainda mais real do que operar corpos já mortos, já que é possível colocar reações e sinais de vitalidade aos corpos digitais. Ou talvez, jogos que permitem que os jogadores sejam inseridos na realidade simulada dos seus jogos favoritos, como surfar em ondas que talvez são muito arriscadas para o usuário ou esquiar em montanhas geladas que sejam muito caras e longe do poder aquisitivo do consumidor do conteúdo digital.

\subsection{Aplicativo Localidades Antigas}

O aplicativo Localidades Antigas foi desenvolvido pelas duas organizações citadas anteriormente, a OverReal e a XPTO. O projeto se iniciou com a XPTO, que teve a ideia do projeto e iniciou o seu desenvolvimento intelectual. $O$ objetivo inicial do projeto era o impacto cultural de fornecer aos usuários conhecimento sobre a história de certas localidades. Seu projeto inicial era 
utilização da realidade aumentada, que é uma tecnologia muito próxima da realidade virtual, porém, com algumas diferenças técnicas, para a visualização de fotos de regiões específicas. Porém, com o avanço tecnológico, foi identificada pela XPTO a oportunidade de se trabalhar com a realidade virtual, através do uso de óculos que são utilizados em parceria com smartphones ou computadores. Ao se deparar com essa tecnologia, a XPTO contrata a OverReal para desenvolver a parte técnica do software de RV que era voltado em específico para a cidade do Rio de Janeiro. Ou seja, a contratação da OverReal foi para criação de apenas um módulo do projeto Localidades Antigas.

No caso específico do módulo do Rio de Janeiro, o conteúdo se resumia em enxergar, através da RV, a Praça Mauá no ano de 1930, e ao mesmo tempo, ter a possibilidade de visita-lo em seu estado atual, com todas as transformações geradas com o passar do tempo e pela ação humana.

\subsection{Realidade Virtual e Marketing Sensorial}

Em paralelo, a estratégia de marketing sensorial ganha forças no mercado brasileiro. A cada dia, são desenvolvidos mais itens que estimulam os sentidos dos consumidores e os convida a conhecer ou se atrelar a uma marca, aumentando a receita gerada pelas vendas e a fidelidade da clientela.

No Brasil a utilização da realidade virtual para fins de marketing ainda é pequena, porém, no exterior temos exemplos de grandes empresas como o Mcdonald, Sak e Alibaba. Um exemplo que pode destacar o mercado de turismo que será abordado a seguir é a rede Best Western, que disponibiliza uma visita aos seus hotéis sem que o cliente em potencial tenha que sair do sofá da sua casa. Utilizando somente a realidade virtual, o mesmo necessita apenas de fazer o download de um aplicativo produzido pela empresa no seu celular ou acessar através do seu celular um site específico, onde, no momento em que ele clicar no link dos quartos desejados, ele coloca o seu celular dentro dos óculos voltados para RV e enxerga o quarto e sua vista como se estivesse dentro do quarto do hotel. 


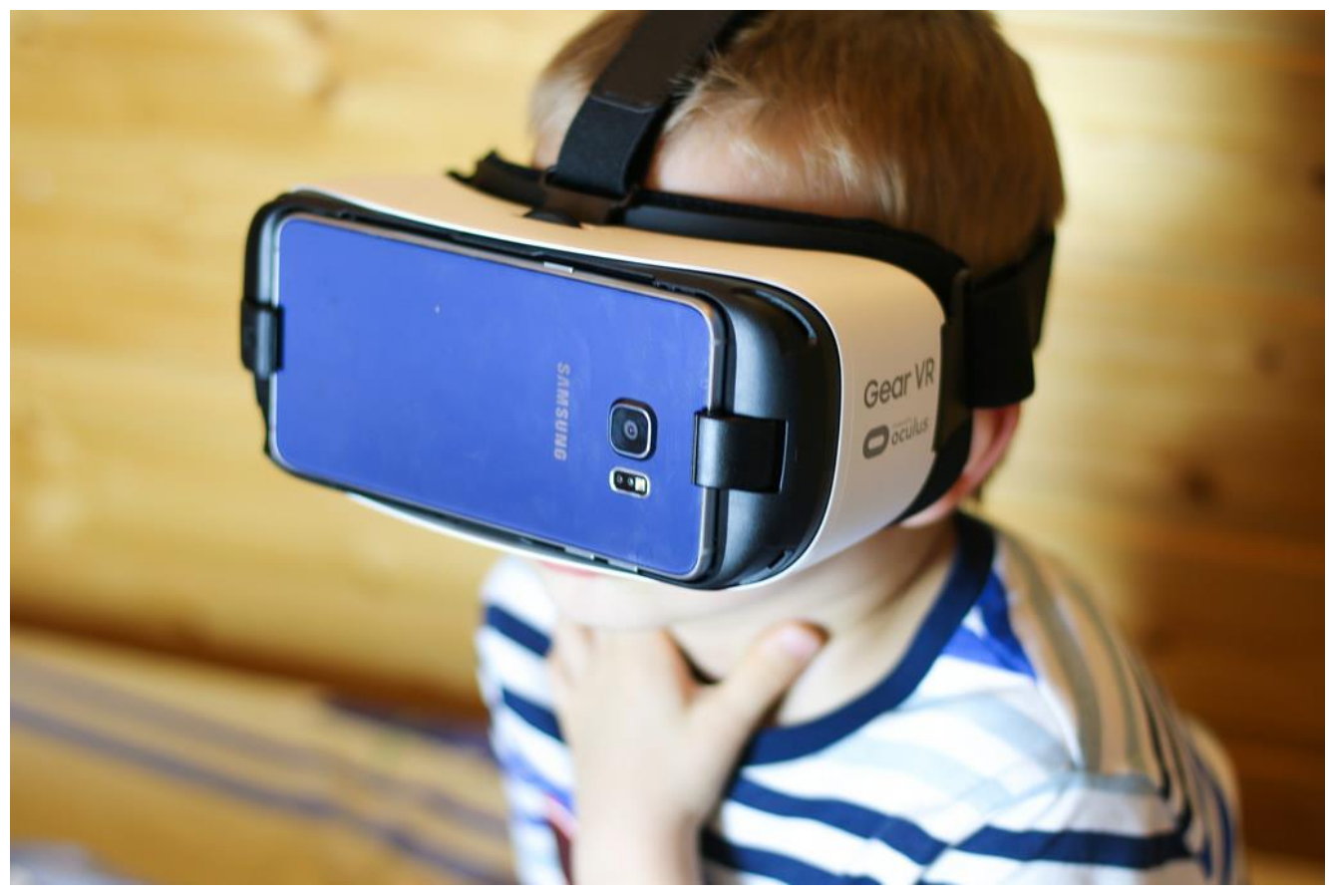

Figura 1: Exemplo de uso dos óculos junto com o celular para RV. Fonte: Google Docs, 2017.

\subsection{Turismo}

Assim como nos diversos mercados, as experiências passaram a ter uma relevância para o turismo que se tornaram mais importantes que os produtos adquiridos durante uma viagem, por exemplo o aumento do número de pessoas realizando viagens chamadas de "mochilão", que são baseadas no pensamento de viajar com o menor custo possível, se preocupando apenas em aproveitar ao máximo as experiências disponibilizadas pelo local visitado. O desejo por experimentar o novo ou o desconhecido, se tornou importante num mundo globalizado em que podemos ter imagens e comprar produtos importados de qualquer lugar sem sair da nossa casa. Dessa forma, a experiência de estar em um local e realizar uma atividade que só podemos ter estando fisicamente presentes se torna essencial em uma viagem.

A tecnologia de realidade virtual não pode reproduzir a realidade de uma viagem por completo. Afinal, você não estará vivendo uma realidade natural, mas sim a digital. De qualquer forma, isso é exatamente o objetivo do marketing sensorial. Promover as vendas através de experiências sensitivas. No caso do turismo, a utilização da imersão virtual pode ser encarada como uma amostra daquilo que o cliente irá usufruir durante a sua viagem. 


\section{Fundamentação Teórica}

\subsection{Marketing Sensorial}

Segundo Kotler (2000), comumente o marketing é reconhecido como a tarefa de criar, fazer promoção e fornecer bens e serviços aos consumidores, independente da natureza destes consumidores, pessoas físicas ou jurídicas. $O$ autor ainda coloca que é de responsabilidade dos profissionais atuantes na área do marketing o envolvimento com os bens, eventos, lugares, etc.

Para a realização de estratégias de marketing bem estruturadas, eficientes e eficazes, o requisito principal é o conhecimento do mercado, dos consumidores e de todos os agentes participantes influenciadores do seu negócio. Além disso, o foco de todas as áreas das empresas deve estar no consumidor. Em como identificar oportunidades de agregar valor ao consumidor. Independente se está influenciando no produto final ou se está apenas adicionando ao conceito e perfil relacionado à marca. Porque nos dias atuais, onde a capacidade de produção iguala a maioria dos competidores, o grande diferencial está na experiência em que o cliente terá ao consumir o seu produto. Ou seja, o produto final torna-se mais um item que deve ser disponibilizado para que a experiência que está sendo vendida seja a ideal. O produto final representa o ator principal de uma peça que contém diversos itens coadjuvantes agregando valor para que o cliente, representado pelo espectador, saia satisfeito com o espetáculo.

Kotler (2000) indica que a orquestração de diferentes serviços e bens desenvolve uma melhor apresentação e comercialização de experiências. Como roteiro para esse espetáculo encontra-se a estratégia de marketing chamada de marketing sensorial ou dos sentidos, que apresenta como principal objetivo proporcionar experiências para a conquista de novos clientes, que sejam fiéis à marca e que aumentem os seus gastos com a mesma. Uma experiência que pode ser levada através da marca e de seus produtos para o cliente ou até mesmo através de amostras que venham incentivar a busca por consumo por parte do cliente em potencial.

Segundo Suárez e Gumiel (2012), marketing sensorial é a utilização de estímulos e fatores que os consumidores identificam através dos sentidos: audição, visão, paladar, tato e olfato. O que no caso mais específico da RV se 
encaixa perfeitamente porque a mesma trabalha com a visão e, se necessário, pode ser trabalhado junto com todos os outros sentidos, sendo necessário somente criar um ambiente de imersão virtual, ou seja, um ambiente manipulado para que todos os sentidos sejam estimulados e levem o usuário do ambiente imersivo a experimentar as sensações do ambiente que ele está visualizando nos seus óculos de imersão virtual.

\subsection{Turismo}

De acordo com Andrade (1998) o turismo envolve uma gama de serviços voltados para planejar, promover e executar viagens, além é claro de serviços como recepcionar, hospedar e atender as pessoas que estão fora de suas moradias cotidianas. Muitas vezes turismo remete a ação de visitar locais diferentes daqueles aonde os visitantes habitam. Neste artigo, que trato mais especificamente do Rio de Janeiro, temos que destacar que turismo também inclui visitas na própria cidade residência a pontos turísticos que possuem alguns dos serviços descritos por Andrade (1998), como recepção, guiamento, gastronomia, etc.

De acordo com Roberto Medina, criador do evento Rock in Rio, em resposta à matéria desenvolvida por Selma Schimidt ao jornal $O$ Globo, foram investidos nos últimos quatro anos no Rio de Janeiro mais de $R \$ 25$ bilhões em infraestrutura. Juntando esse valor financeiro investido e a beleza natural da cidade, o Rio viria a se tornar um dos maiores ativos do mundo no setor de turismo. Esse valor investido revela que a principal característica do Rio é o investimento no mercado de turismo e também encontra nele uma das suas maiores fontes de retorno financeiro. Ainda de acordo com a matéria, com o investimento realizado, a cidade teria a oportunidade de desenvolver projetos turísticos que resultarão em um lucro potencial de cerca de $\mathrm{R} \$ 200$ milhões.

Sendo assim, as oportunidades do mercado de turismo no Rio de Janeiro, em específico, apresentam grandes possibilidades de investimento num curto prazo. Desenvolvendo-se as ferramentas e produtos corretos, é possível ir ao encontro dessas oportunidades e desenvolver negócios lucrativos.

\subsection{Realidade Virtual}

Os autores Kirner e Siscoutto (2007) definem a Realidade Virtual como uma interface avançada para aplicações computacionais, que dá ao usuário o direito 
de navegar e interagir, em tempo real, com um ambiente que foi produzido, tridimensionalmente em computador, utilizando dispositivos voltados para diferentes sentidos do corpo humano

Como dito no início deste artigo, a RV nos permite imergir em uma realidade totalmente digital, criada, planejada, desenvolvida e controlada. Um fator importante que é descrito por Kirner e Siscoutto (2007) é a capacidade de imersão completa do usuário da RV. no ambiente simulado. Isso se dá através do uso dos dispositivos multissensoriais citados.

Quando o usuário da RV. passa a estar com todos ou a maioria de seus sentidos imersos na dimensão virtual criada para o mesmo, chamamos 0 processo de Imersão Virtual. Dessa forma, o usuário perde grande ou toda a percepção da realidade natural e passa a responder somente aos estímulos criados através da RV. Pode-se colocar efeitos auditivos através do uso de fones de ouvido. No caso de a imersão virtual acontecer em um local isolado acusticamente, podem ser realizados efeitos sonoros através de caixas de som ou sonoplastia. Obviamente, os efeitos sonoros devem ser condizentes com aquilo que está sendo visualizado pelo usuário. Outro fator que pode ser utilizado é o tato. O usuário pode ser levado a pisar em diferentes pisos que criarão a sensação esperada de acordo com aquilo que está visualizando através dos óculos.

Outra ação interessante é a utilização de aparelhos que venham estimular a sensação térmica da realidade digital vivida. Para exemplificar, podemos citar o ambiente de imersão virtual desenvolvido durante feiras expositivas da séria Game Of Thrones, realizada em algumas cidades do Estados Unidos. O ambiente de imersão virtual simulava o elevador que os personagens precisavam utilizar para subir até o topo da grande muralha gelada. Sendo assim, foram utilizados, além dos óculos rift, item básico para a prática da realidade virtual, sistema de sonorização 4D e também máquinas de vento que sopravam ar gelado e com força sobre os usuários do material. Tudo isso se desenvolve dentro de um elevador real que ficava preso ao chão. 


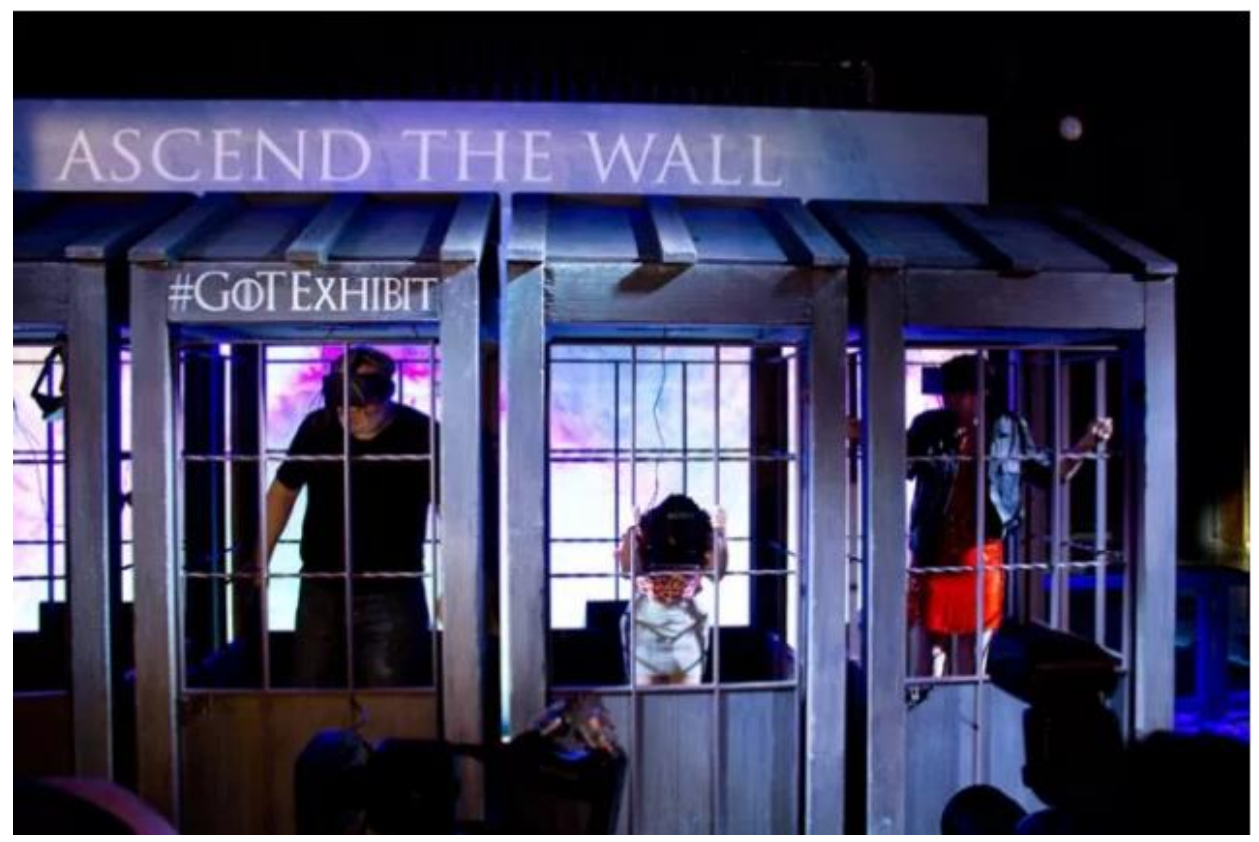

Figura 2: Exemplo de ambiente de imersão virtual inspirado em Game of Thrones - Fonte: Portal Realidade Virtual, 2017. 


\section{Metodologia de Pesquisa}

\subsection{Escolha e Apresentação do Método}

No capítulo que se inicia escolheremos o método a ser utilizado para se testar as oportunidades possivelmente existentes de se utilizar no mercado de turismo a estratégia de marketing sensorial através das ferramentas da realidade virtual e realidade aumentada.

Naresh Malhotra (2006) indica que a pesquisa em marketing é definida como a busca por identificar, coletar, analisar e disseminar de forma sistemática e objetiva as informações. De acordo com ele, essas ações facilitam a tomada de decisão e identificação de problemas no marketing. O mesmo autor ainda classifica o termo "problema" como sendo uma oportunidade. A partir disso, as pesquisas desenvolvidas buscam aproveitar essas oportunidades.

Ao tratarmos de conceitos como a pesquisa em marketing, relacionados à disciplina da Administração, temos a característica de identificar um processo muito bem estruturado, que quando respeitado e aplicado de forma correta aumenta a probabilidade de termos maior veracidade nas informações encontradas. O que também vai facilitar a análise das informações e as decisões a serem tomadas. Identificamos a fases do processo proposto por Malhotra (2006) a seguir:

\section{Definição do Problema.}

Onde se estabelece o objetivo do estudo e questionamento que servirão como guias durante o desenvolvimento da pesquisa. Nessa fase também se avalia os dados secundários, itens encontrados e pesquisas feitas com objetivos diferentes, mas que apresentam relevância prática no problema da pesquisa em desenvolvimento.

II. Desenvolvimento da abordagem para o problema.

O segundo passo une a estrutura analítica aos exemplos aplicados, a especificidade das informações e produção de questões de pesquisa e testes de hipótese, que facilitam a produção do questionário que será utilizado.

III. Formulação do projeto para pesquisa.

O terceiro passo é a formulação do programa de pesquisa especificando as ações necessárias para se alcançar os dados necessários. Definindo assim se a 
pesquisa terá o caráter exploratório, descritivo ou causal, caráteres que serão melhor explicados adiante. Assim como a linha de raciocínio que será tomada pela pesquisa, sendo com uma visão qualitativa ou quantitativa. Neste momento também é necessário a definição do questionário que será utilizado, pois diversos aspectos do mesmo, como a sequência de perguntas e variação das possibilidades, entre outros aspectos, influenciariam em tornar a pesquisa mais confiável e relevantes.

IV. Execução do trabalho de campo e coleta de dados.

Nesta fase, os pesquisadores devem ir à campo, enviar questionários, responde-los, são feitas avaliações e interações com os entrevistados que foram previamente planejados e selecionados.

V. Preparação e análise dos dados

Separar e analisar o conteúdo obtido através das pesquisas feitas em campo é o que define esta penúltima etapa, com o objetivo de através do cruzamento dos dados obtidos, produzir uma tradução com as principais informações e da aplicação das mesmas. Outro fator importante é comparar essas mesmas informações obtidas com os objetivos definidos previamente.

VI.Elaboração e apresentação do relatório.

A última fase é onde um relatório será preparado e apresentado, representando alternativas que podem influenciar na tomada de decisão e embasamento para pesquisas que podem ser desenvolvidas no futuro.

Com base no processo descrito, este artigo busca através de entrevistas encontrar através do olhar de profissionais e consumidores de tecnologia e produtos e serviços relacionados ao mercado de turismo, para a implantação da realidade virtual em conjunto com o marketing sensorial no mercado de turismo. Buscando fazer essas entrevistas de forma presencial ou de forma que o contato entre entrevistador e entrevistado permita a maior captação de mensagens por parte do entrevistado. Ou seja, não simplesmente a mensagem falada pelo entrevistado, mas também suas reações que irão facilitar a real intenção do respondente durante suas falas.

\subsection{Tipos de Pesquisa}

$\mathrm{Na}$ terceira etapa é necessário o conhecimento acerca dos tipos de pesquisa existentes. Já que é nessa etapa que se elabora o modelo de pesquisa e a definição do tipo apto que facilitará a aparição de resultados e informações mais exatas em relação ao problema apresentado. 
Seguindo o pensamento de Malhotra (2006), os modelos de pesquisa de marketing são classificados em duas categorias: conclusivo e exploratório. De acordo com o autor, a pesquisa conclusiva é desenvolvida para cooperar com o tomador de decisão a analisar e escolher a melhor atitude de determinada situação. Na maioria das vezes é utilizada de forma a evidenciar e analisar os resultados da pesquisa exploratória desenvolvida anteriormente. O teste das hipóteses e validação da relação de dados são os principais objetivos desse tipo de pesquisa. Além de ter um procedimento mais estruturado de pesquisa, mais formal e possuir amostras maiores e de maior representação quando comparada com a pesquisa exploratória, permitindo-nos alcançar dados mais conclusivos.

Esse tipo de pesquisa possui duas subcategorias, que são descritiva e causal. A descritiva busca detalhar as funcionalidades e características do mercado, além de ela considerar os dados secundários, conteúdo de observação, construir painéis e realizar levantamentos. Malhotra (2006) informa que os estudos descritivos mais relevantes são relacionados a vendas, de percepção e comportamento dos consumidores, além de estudar o mercado no âmbito macroeconômico e externo a empresa. A causal por sua vez tem como característica a verificação da existência ou não da relação de causa e efeito entre as variáveis presentes no problema. Dessa forma, se realiza esse tipo de pesquisa conclusiva em experimentos que tem suas variáveis independentes manipuladas e identifica-se se há ligação ou influência entre as mesmas.

Ainda seguindo o raciocínio do autor, a pesquisa exploratória tem como objetivo a busca por possibilidades, ideias e conteúdo acerca do problema pesquisado. Os dados apresentados na pesquisa não possuem uma definição exata. Sua estrutura é flexível e geralmente apresenta uma amostra pequena quando comparada com a população que possui relação com o problema. Por essas características, após a realização da pesquisa exploratória, costuma-se realizar a pesquisa conclusiva. Porém, é através da pesquisa exploratória que os pesquisadores costumam encontrar inspirações para a continuação ideal do projeto.

Tendo como característica a abertura de oportunidades em novos mercados para a RV e para o marketing sensorial, essa pesquisa opta por ser exploratória, buscando possibilidades e ideias que venham agregar ao conhecimento e ao esforço daqueles que estiverem buscando a realização dessa penetração de mercado. Tendo como uma das principais características a falta de uma conclusão determinadora do futuro dessas ações, mas sim o incentivo para se buscar novas informações que venham agregar para com ela. 


\subsection{Relevância do Questionário e das Entrevistas}

A partir das informações contidas neste capítulo, foram desenvolvidas entrevistas com os gestores das empresas OverReal e XPTO, Marlon Braga e José da Silva respectivamente. Utilizando-se de uma pesquisa qualitativa para este fim.

Além dos profissionais, devido à dificuldade de se encontrar muitos turistas que haviam utilizado o aplicativo Localidades Antigas, já que os mesmos, em sua maioria, não eram habitantes do Rio de Janeiro e não possuíam qualquer vínculo com os desenvolvedores do programa, foi desenvolvido um segundo questionário também qualitativo para identificar a visão dos turistas e usuários em relação a essa linha de aplicativos que são voltados para o mercado de turismo. Ambos os questionários foram respondidos ou de forma presencial ou através de meios de comunicação que possuem ligação através de vídeo, como Skype, de modo que foram entrevistados com o objetivo de que se alcançasse o maior enriquecimento possível através da resposta dos mesmos. As entrevistas realizadas podem ser classificadas como pesquisas exploratórias.

Como gestores de suas empresas, as respostas de Marlon Braga e José da Silva são de grande representatividade para o projeto desenvolvido através deste artigo. Afinal, além de terem o "know-how" técnico para o desenvolvimento de produtos que se utilizam da RV e da RA, tem a experiência de já ter os seus produtos no mercado. Outro fator interessante é o fato de que ambas as empresas pertencem à classificação de pequeno-médio porte, identificando que o aporte de capital inicial não tem necessidade de ser elevado para se desenvolver algo suficientemente agradável aos clientes.

\subsection{Delimitações do Estudo}

A amostra considerada para o desenvolvimento do trabalho é não probabilística. Isso significa que a probabilidade de participação não é igual para todos os indivíduos da população, de acordo com o pensamento de Malhotra (2006).

Uma informação muito relevante é a forma pela qual o questionário chegou até os participantes. As perguntas foram feitas pessoalmente a cada um dos informantes, onde houve gravações de áudio de cada uma das repostas de cada um dos participantes. Com o objetivo de não perder possíveis detalhes nas 
respostas dos mesmos, o que pode enriquecer o conteúdo do artigo. O questionário utilizado para os gestores e o questionário utilizado para os usuários dos aplicativos, está disponibilizado nos anexos do trabalho.

E como dito anteriormente, há relevância no questionário desenvolvido devido a possibilidade de utilização do mesmo para o desenvolvimento de novos questionários, com foco quantitativo, conclusivo, cooperando para o desenvolvimento de futuras pesquisas que irão cooperar para o entendimento dos mercados tecnológico e de turismo, além da aplicabilidade de estratégias de marketing. 


\section{Apresentação e Análise dos Resultados}

\subsection{Entrevistas}

De início desenvolvemos uma entrevista com José da Silva, Sócio fundador da XPTO, que, através do seu conhecimento de produzir conteúdos audiovisuais, tem como foco clientes que pertencem ao meio cultural, como museus espalhados pelo Brasil. Sendo assim, José da Silva reconhece a necessidade de se produzir conteúdos que envolvam os usuários e captem sua atenção. Além, é claro, de criar desejo ou curiosidade para buscar mais informações sobre o tema de suas exposições, etc. Como dito por ele, o aplicativo Localidades Antigas foi criado com o propósito de alcançar o mercado cultural. Apesar de não ter sido criado com o objetivo de inserção no mercado de turismo, o aplicativo alcançou esse nicho pelo fato de ter sido disponibilizado para a utilização dentro de museus famosos do Rio de Janeiro, como o Museu do Amanhã. José da Silva teve contato com usuários do aplicativo no Museu do Amanhã e indicou a participação dos mesmos para o nosso artigo através da resposta do questionário voltado para os usuários. José da Silva ainda informou que uma segunda intenção era a disponibilização do aplicativo para instituições de ensino, que quisessem, por exemplo, lecionar sobre a estrutura geográfica e a disposição de pontos importantes do Rio, como a Praça Mauá nos anos 30, ou de diversas outras cidades em momentos diferentes da história do Brasil. Porém, esse projeto não correu como planejado.

Quando perguntado acerca dos motivos pelos quais ele não planejou ter como principal objetivo o mercado turístico, José indica que identifica como principal dificuldade a capacidade de se alcançar esse público. Trata-se de ser um público obviamente muito disperso e que varia muito em questões de idade, renda, preferência por locais, etc. Nesse ponto, é importante ressaltar uma das hipóteses levantadas como oportunidade para desenvolvimento do uso das tecnologias com o mercado de turismo, que é a parceria entre as empresas produtoras de conteúdo tecnológico e as empresas do setor turístico, por exemplo hotéis, agências de turismo, atrações como museus, parques, entre outros. Afinal, as empresas de turismo possuem o conhecimento e contato com o público que consome os serviços e produtos deste mercado, facilitando assim 
a exposição do conteúdo e contato entre firma e cliente, ou possíveis novos clientes.

Quanto a questão de "praça" onde o produto foi disponibilizado, foi respondido que o aplicativo, além de ter sido disponibilizado em museus, para uso dos visitantes, junto com óculos voltados para a RV, também foi disponibilizado em uma loja virtual voltada para aplicativos de celulares ou tablets com sistema operacional Android, chamada Play Store. O aplicativo, durante todo o período de venda na Play Store, inclusive até o dia de hoje, permanece gratuito para o download. Porém, acredito que devemos levar em consideração, que aqueles que utilizaram o aplicativo no museu em que foi disponibilizado, apesar de não terem comprado o ingresso do museu especificamente para a utilização do aplicativo, tiveram que dispender dinheiro para ter acesso ao mesmo.

De acordo com José, a aceitação do aplicativo é excelente. Muitos são aqueles que elogiam e buscam cooperar com ideias e propostas em relação ao aplicativo. Porém, a demanda não acompanha a aceitação. A aquisição ainda é baixa quando comparada com a quantidade de pessoas que foram até 0 idealizador do projeto elogiar o trabalho e seu desenvolvimento. Posteriormente, iremos discorrer sobre essa questão. Perguntamos aos usuários o porquê dessa diferença com o objetivo de entender essa questão.

Um momento interessante da entrevista foi a resposta dada por José quando perguntado qual era a visão dele em relação ao potencial da RV no mercado de turismo. Ele confessa que, se fosse um cliente em potencial não seria adepto ao uso do produto. Segundo ele, a utilização desse instrumento iria roubar a possível visão inédita, a experiência do inédito de uma viagem. Ou seja, a utilização da RV para mostrar pontos turísticos do Rio de Janeiro para turistas que queiram visitar a cidade, roubaria dos mesmos o efeito da beleza do talvez "amor à primeira vista". Ele apresenta como alternativa de mercado para a RV o foco em experiências em lugares de muito difícil acesso ou para pessoas que não consigam acessar determinados pontos turísticos. Por exemplo, pessoas idosas, deficientes físicos ou pessoas que não possam acessar o topo de uma montanha por problemas de qualquer natureza. Por exemplo, a Pedra da Gávea é considerada como uma das trilhas mais difíceis da cidade do Rio de acordo com especialistas da área.

Atendo o próprio aplicativo Localidades Antigas como exemplo, ele explica que a utilização da RV como forma de vivenciar o estilo de vida de uma cidade como o Rio de Janeiro em épocas passadas é algo que impactaria ele 
positivamente como cliente do mercado de turismo. Porque ele particularmente se interessaria mais por conhecer mais a cultura do local e também de certa forma explicaria muitas questões sociais vividas nos dias atuais. Mas é importante ressaltar que essa é a visão de José como empresário. Questionamos os consumidores do aplicativo para ver se na prática essa visão permanece.

Em seguida, a pesquisa foi realizada com Marlon Braga, que, além de possuir o conhecimento técnico das tecnologias $R V$ e RA, é um jovem empreendedor, que tem a sua empresa voltada para a produção de softwares específicos para essas tecnologias. A sua juventude permite ainda a capacidade de identificação de tendências de consumo das tecnologias da população mais jovem da sociedade.

Marlon destaca que o projeto Localidades Antigas é excelente como um promovedor do uso da RV. Ele se baseia no fato de que, segundo ele, nos dias de hoje, a maioria dos projetos que envolvem o uso da tecnologia são voltados para coisas lúdicas, que não fazem parte da nossa realidade e que acrescentam basicamente a qualidade de entreter o usuário, sem adicionar conteúdo relevante o suficiente para ensinar, qualificar seus usuários, trazer experiências que possam ser consideradas enriquecedoras, diferente do aplicativo Localidades Antigas. Assim como José, Marlon pensa que as pessoas têm o desejo de conhecimento por história, por saber o que aconteceu no passado. De acordo com ele, não existe uma pessoa que não vá a Roma que não queira passar pelo Coliseu, pela Torre de Pisa. Da mesma forma o Rio. Apesar de a cidade ser reconhecida por suas paisagens naturais, a mesma já foi a casa de imperadores, já foi a capital de um país e sim, é possível conquistar um público de turistas interessado nesta história do local.

Com sua visão técnica da RV, Marlon informa que o uso dos óculos voltados para a RV, por exemplo, o Cardboard que é um de custo mais baixo e são de extrema importância para o uso da tecnologia. Caso o mesmo não aconteça, a experiência de uso da RV perde e muito a qualidade e a sua característica principal, como foi dito anteriormente. Afinal, a capacidade de imersão é "zero", sendo assim, o usuário estará apenas vendo um vídeo no seu celular, ao invés de imergir à $\mathrm{RV}$. 


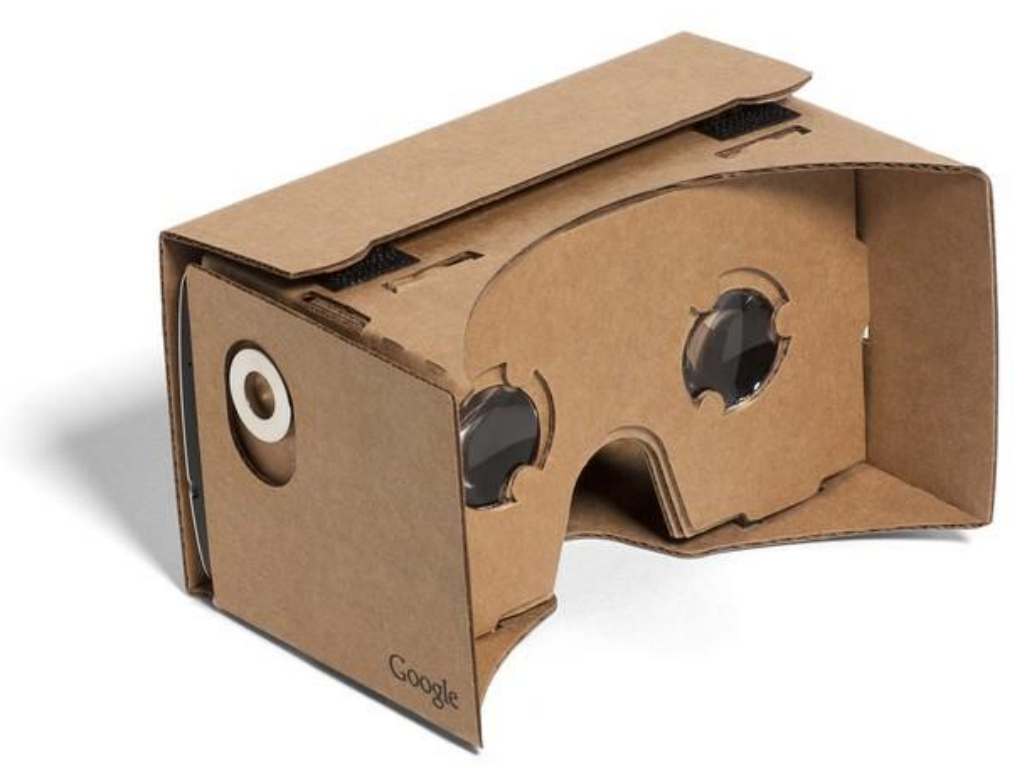

Figura 3: Google Cardboard. Exemplo de Óculos para RV - Fonte: Unimersiv, 2016.

Essa questão quanto ao uso dos óculos é de extrema relevância e o proprietário da OverReal identifica isso como uma barreira para a expansão da comercialização de produtos voltados para RA e RV. O principal problema é o custo para se adquirir os óculos e o pouco conhecimento que se tem em relação a tecnologia. Segundo ele, em outros países como Estados Unidos, Japão e países mais ricos da Europa, o conhecimento e o acesso a esse tipo de tecnologia está muito a frente do que o Rio de Janeiro consegue alcançar. Porém, como entusiasta do mercado, ele apresenta como opção a disponibilização da tecnologia pelos vendedores de produtores turísticos tecnológicos. Por exemplo, o Museu do Amanhã disponibilizou óculos apropriados para o consumo dos visitantes ou lojas de pacotes de intercâmbio, parques de diversão e pontos turísticos que possam fazer o mesmo. Isso, além de divulgar seus produtos e serviços, serviria para promover o uso da RV.

Mais otimista quanto ao uso da tecnologia para o mercado de turismo, Marlon acredita que tem sim potencial para a utilização como forma de dar ao cliente uma prova daquilo que ele pode ter em suas viagens, mas que a RV nunca irá substituir a viagem real. Apesar de ser possível fazer uma imersão virtual com o usuário, se utilizando de aparelhos e técnicas que vão potencializar a experiência através da tecnologia, nunca os sentimentos aos quais os turistas estarão expostos serão iguais aos dos usuários da RV. Sempre as viagens reais, potencializarão muito mais os sentimentos e experiências dos viajantes. 


\subsection{Descrição do perfil de usuários entrevistados}

Devido a dificuldade de se ter acesso aos consumidores do aplicativo, a pesquisa se mostrou mais próxima do resultado ideal através da entrevista daqueles que experimentaram a tecnologia, obtendo por tanto um fim mais qualitativo do que quantitativo através de uma grande amostra de respostas. Seja por sua dispersão, afinal em sua maioria foram visitantes do Museu do Amanhã ou também pelo fato de as pessoas conseguirem fazer o download do aplicativo de qualquer lugar do mundo através da loja virtual de aplicativos. Sendo assim, a nossa amostra de consumidores respondentes se trata de pessoas que foram indicadas pelos desenvolvedores do projeto, tendo sido conhecidas durante a realização do projeto no museu.

Com a idade entre 19 a 32 anos, sendo sua maioria próxima dos 19 anos, a amostra conta com indivíduos que apresentam diferentes faixas de renda em suas casas, sendo maioria pertencente à faixa de até no máximo dois salários mínimos. O que identifica o baixo poder aquisitivo da amostra. Outro fator que representa a amostra é que a grande maioria da amostra é habitante da cidade do Rio de Janeiro. Há também representantes de São Paulo e Minas Gerais. O que os qualifica é o fato de, que além de serem visitantes de pontos turísticos do Rio, foram ou são usuários do aplicativo.

Tabela 1 - Dados Demográficos dos Entrevistados

\begin{tabular}{|l|l|l|l|l|l|}
\hline Nome & Sexo & Idade & Estado & Cidade & $\begin{array}{l}\text { Faixa de } \\
\text { Renda } \\
\text { Familiar }\end{array}$ \\
\hline GF & Masculino & 19 & RJ & $\begin{array}{l}\text { Rio de } \\
\text { Janeiro }\end{array}$ & $\begin{array}{l}\text { Até } \\
\text { Salários } \\
\text { Mínimos }\end{array}$ \\
\hline
\end{tabular}




\begin{tabular}{|c|c|c|c|c|c|}
\hline PA & Masculino & 23 & RJ & $\begin{array}{ll}\text { Rio } & \text { de } \\
\text { Janeiro } & \end{array}$ & $\begin{array}{l}\text { De } 10 \text { a } \\
20 \\
\text { Salários } \\
\text { Mínimos }\end{array}$ \\
\hline NV & Feminino & 28 & SP & Valinhos & $\begin{array}{l}\text { De } 4 \text { a } 10 \\
\text { Salários } \\
\text { Mínimos }\end{array}$ \\
\hline IA & Masculino & 19 & RJ & $\begin{array}{l}\text { Rio de } \\
\text { Janeiro }\end{array}$ & $\begin{array}{l}\text { Até } 2 \\
\text { Salários } \\
\text { Mínimos }\end{array}$ \\
\hline TP & Masculino & 30 & RJ & $\begin{array}{l}\text { Rio de } \\
\text { Janeiro }\end{array}$ & $\begin{array}{l}\text { Até } 2 \\
\text { Salários } \\
\text { Mínimos }\end{array}$ \\
\hline RA & Feminino & 26 & RJ & $\begin{array}{ll}\text { Rio de } & \text { de } \\
\text { Janeiro } & \end{array}$ & $\begin{array}{l}\text { Até } 2 \\
\text { Salários } \\
\text { Mínimos }\end{array}$ \\
\hline MF & Masculino & 32 & RJ & $\begin{array}{ll}\text { Rio } & \text { de } \\
\text { Janeiro } & \end{array}$ & $\begin{array}{l}\text { Até } 2 \\
\text { Salários } \\
\text { Mínimos }\end{array}$ \\
\hline GR & Masculino & 19 & MG & $\begin{array}{ll}\text { Juiz } & \text { de } \\
\text { Fora } & \end{array}$ & $\begin{array}{l}\text { Até } 2 \\
\text { Salários } \\
\text { Mínimos }\end{array}$ \\
\hline RB & Masculino & 26 & RJ & $\begin{array}{l}\text { Rio de } \\
\text { Janeiro }\end{array}$ & $\begin{array}{l}\text { Até } 2 \\
\text { Salários } \\
\text { Mínimos }\end{array}$ \\
\hline FC & Masculino & 27 & RJ & $\begin{array}{l}\text { Rio de } \\
\text { Janeiro }\end{array}$ & $\begin{array}{l}\text { De } 10 \text { a } \\
20 \\
\text { Salários } \\
\text { Mínimos }\end{array}$ \\
\hline
\end{tabular}

\subsection{Análise dos Resultados}

Além da resposta dos empresários, é interessante analisarmos as respostas dos consumidores, que são o público alvo do produto tecnológico e por isso as suas respostas se tornam tão importantes ou até mais importantes 
que as dos empresários com seus conhecimentos técnicos e profissionais, devido ao fato de que no fim das contas a opinião deles influenciará seu consumo e por consequência a possível receita gerada através dos produtos criados.

Foram dez respondentes. Isso se dá devido a dois fatores, além do já citado, que é a dificuldade de se alcançar aqueles que já consumiram o produto durante a exposição, devido ao fato de pertencerem a diferentes localidades do país e não terem sido fornecidos mais informações do que os nomes de alguns indivíduos, o que dificulta o processo de encontrar esses indivíduos. O outro fator foi o fato de a tecnologia necessitar de celulares que tenham aparatos tecnológicos que só são encontrados em aparelhos recém-lançados e de alto custo de aquisição. Além disso, é necessário adquirir os óculos de RV. Ou seja, mesmo que a pessoa tenha o celular, se não tiver os óculos, de nada adianta para a utilização da tecnologia. Dos 10 respondentes, somente três possuíam um celular capaz de reproduzir a tecnologia e possuía os óculos propícios para isso. Vale a pena considerar que desses três, dois possuem renda acima de 4 salários mínimos. E todos os outros respondentes possuem renda inferior a 4 salários mínimos. Confirmando uma barreira que havia sido citada pelo empresário Marlon.

Em paralelo a dificuldade de se adquirir no Brasil um celular considerado "de ponta", que tenha os recursos necessários para se reproduzir o conteúdo $R V$, existe a questão de que não são todas as bases de aparelhos que possuem o aplicativo disponível para uso, já que o mesmo se encontra apto para download somente na Play Store, loja de aplicativos dos modelos Android. Dessa forma, alguns respondentes que possuem celulares recém-lançados da Apple, que possuem recursos suficientes para o desenvolvimento da RV, porém, não possuem o aplicativo disponível para download por serem modelos da base ios.

Um fator interessante, descoberto através da pesquisa, é que praticamente todos os entrevistados souberam definir, ainda que de forma simplória, o que é realidade virtual. Obviamente, no momento de definir remetem as experiências anteriores em que tiveram contato com a tecnologia. Somente um entrevistado não soube definir o conceito. Nisso percebemos que devido às respostas bastante práticas e menos teóricas acerca do conteúdo, o conceito não obteve um conhecimento amplo por parte da população. O que impede uma maior demanda do mesmo. 
Uma pergunta que possui uma visão mais relacionada ao poder de influência em relação ao desejo de compra dos usuários foi quanto a possibilidade de a utilização do aplicativo gerar no usuário o desejo de conhecer mais o Rio de Janeiro. Uma resposta interessante foi a do I.A., estudante de arquitetura da PUC-Rio, morador da cidade do Rio e que mesmo assim disse ter sido influenciado pelo desejo de conhecer mais sobre a cidade do Rio pelo fato de que, segundo ele através de um contato tridimensional e uma experiência visual mais imersiva é gerado um desejo maior. E por mais que possibilite o ângulo desejável para cada indivíduo, ele acredita que essa experiência só fomente mais o desejo de conhecer realmente o lugar. Os demais respondentes, não se apegaram tanto a fatores técnicos da RV, mas sim ao fato do despertar da curiosidade em conhecer melhor a cidade que estão visitando ou habitando. Outro fator que foi comentado é o fator histórico, que desenvolveu a vontade de comparar o antigo com o atual. Somente um respondente apresentou a falta de estímulo por conhecer mais a cidade e justificou o fato por ser morador da cidade.

Como consequência ou conformidade à pergunta anterior, todos os respondentes concordaram que a utilização da tecnologia desenvolveu neles uma maior empatia, carinho pela cidade. Ou seja, um maior apego emocional em relação ao Rio. Valendo a pena destacar o comentário de F.C. que acredita que por melhor que seja o fato de você se apegar emocionalmente à algo, isso aumenta a potencialidade de uma possível frustração futura. O que olhando pelo ponto de vista do negócio, pode gerar um marketing "boca-a-boca" muito negativo para a cidade e para os produtos turísticos atrelados à ela.

As duas perguntas seguintes foram desenvolvidas visando testar a utilização de uma estratégia de marketing sensorial em parceria com o conceito de RV. Perguntamos aos colaboradores se uma empresa voltada para o mercado de turismo, que se utilizasse da RV para que os seus clientes em potencial pudessem ter uma prova, uma amostra de como seriam suas viagens, seus passeios durante a viagem ou outras atividades atreladas à viagem, teriam vantagem competitiva em relação aos concorrentes que não possuíssem o mesmo recurso. Todos foram unânimes na resposta que sim. Segundo eles isso facilitaria a definição quanto a decisão de que local seria visitado. Ou seja, se uma agência de viagens apresentasse diferentes vídeos para diferentes países ou cidades, facilitaria aos seus clientes escolher qual seria o seu destino de preferência, porém, na pergunta seguinte, quando perguntados quanto ao item de maior influência no momento de adquirir um pacote de viagens seria o preço. 
Ou seja, por mais que uma empresa se dispenda de investimento para colocar em prática esses "mostruários digitais", ela teria que buscar ser competitiva no preço final de seus produtos. Porém, é importante mencionar também que a amostra conta com uma grande maioria de pessoas de baixo poder aquisitivo, fazendo com que o valor a ser utilizado no momento de adquirir um produto tenha potencialmente uma relevância maior do que em outras faixas de renda.

Aproximando-nos do fim da entrevista, perguntamos aos entrevistados se já tinham tido a experiência de utilizar a RV durante algum processo de decisão em suas vidas e como tinha sido essa experiência. Somente um entrevistado disse ter tido a oportunidade de se utilizar da tecnologia durante um processo decisório. O mesmo indicou que por trabalhar com programação computacional isso foi excelente, pois aconteceu durante um processo de compra de itens que serviriam para a sua carreira profissional e isso fez com que a partir de então ele investisse numa linha de produtos até os dias de hoje. Os outros nove entrevistados por sua vez nunca tiveram a oportunidade de se utilizar deste recurso durante algum processo de decisão em suas vidas.

A última pergunta foi com o objetivo de identificar oportunidades no mercado de aplicativos para RV. Perguntamos aos consumidores se, no caso de eles terem os aparatos tecnológicos necessários para realizar a imersão virtual (celular e óculos de RV), consumiriam um aplicativo que os permitissem viajar e visitar diferentes países e pontos turísticos desses países. Mais uma vez a grande maioria respondeu com grande convicção que com toda certeza iriam consumir o produto. Porém, de acordo com a visão de R.B., ele não consumiria esse produto, a menos que o mesmo possuísse meios que criassem interatividade ou gameficação entre os usuários. Lembrando que, de acordo com Fabrícia Pimenta (2013), gameficação é a utilização de técnicas e aparelhagens de jogos em realidades não pertencentes ao mundo dos jogos, influenciando assim as atitudes e os apectos motivacionais dos usuários. R.B. diz que a falta de disponibilidade dos recursos citados por eles transformariam o aplicativo em um recurso semelhante ao Google Maps e que por isso ele não enxergaria utilidade ou interessante em usufruir do mesmo. O Google Maps é um aplicativo produzido pela empresa Google, onde além de se ter mapas e recurso de GPS, é possível utilizar para se enxergar locais através de imagens produzidas por câmeras 360ำ, simulando a visão humana dos pontos filmados. 


\section{Conclusões}

A partir das pesquisas realizadas, podemos indicar que ainda há uma falta de conhecimento acerca da tecnologia muito grande. Pois a maioria dos consumidores que responderam, mesmo tendo tido algum contato com a $R V$, não foram possíveis de fazer definições conclusivas sobre a tecnologia, conclusões técnicas. Isso demonstra que ainda há uma falta de conhecimento por parte da população. Isso pode se dar pelo fato de fatores econômicos devido ao custo de aquisição do material necessário, em comparação com o poder de aquisição dos respondentes ou devido a falta de promoção da tecnologia por parte do mercado. Essa falta de promoção por parte do mercado carioca, além de ser possivelmente uma causa, pode ser também uma consequência da primeira possível causa citada. Ou seja, já que a tecnologia é cara, até mesmo o mercado tem dificuldade de adquirir e colocar em disponibilidade para seus consumidores.

Quanto a questão de alto custo do material, essa pesquisa sendo exploratória pode estimular o estudo para uma possível pesquisa com o interesse de se encontrar formas de baixar o custo e por consequência o preço final de celulares e óculos de RV. Ou então, simplesmente criar aparelhos específicos para essa tecnologia que tenham valor de mercado mais baixo e feito buscando atingir o público de rendas mais baixas. Além disso, é possível pensar em tecnologias que sirvam para diferentes redes de aparelhos, por exemplo, para a rede Android e ios ao mesmo tempo. Sendo assim, pessoas que tenham adquirido celulares caros e de alta tecnologia, não seriam punidos por não terem os aplicativos disponíveis em suas redes de aparelhos.

Outro assunto interessante que é importante realizar pesquisas mais conclusivas é quanto possíveis temas utilizados nos aplicativos desenvolvidos com RV para se conquistar o público alvo. Como foi visto, o critério histórico da cidade do Rio de Janeiro obteve sucesso, porém, pesquisas quantitativas aferindo diferentes temas podem cooperar para a conclusão de qual o tema turístico é de melhor abordagem e que conquistará o público-alvo. O que enfatiza o que foi dito por Kotler (2000) em relação a necessidade de criar, fazer promoção e fornecer bens e serviços aos consumidores. Se não obtiver 
conhecimento do que é desejado pelos consumidores de conteúdo digital, não haverá sucesso com a venda do mesmo.

Podemos perceber através da pesquisa que há interesse por parte dos consumidores em se ter as provas, "degustações" através da RV dos passeios e locais que serão possivelmente visitados, dessa forma a OverReal apresentou que após essa experiência passou a desenvolver projetos em parcerias com redes hoteleiras buscando não apenas otimizar os treinamentos de seus funcionários, como também de apresentar melhores formas de se promover os produtos destes hotéis. Como foi exemplificado com a rede de hotéis Best Western, aproveitando esta oportunidade nas redes hoteleiras cariocas, em parceria com a empresa de consultoria hoteleira Governança.com. O que coloca em prática o que também foi dito por Kotler (2000) quanto a orquestração de serviços e bens, desenvolvendo uma melhor apresentação e comercialização de experiências.

É interessante a busca por parceria governamental na busca de incentivos para o desenvolvimento e promoção desse tipo de marketing, haja a visto o investimento realizado na cidade do Rio de Janeiro e a necessidade se aumentarem as receitas através do turismo. Se há uma oportunidade de se aumentar a promoção da cidade, causar mais empatia junto aos seus possíveis visitantes, porque não buscar um incentivo governamental, nem que seja através da diminuição de impostos para produtos dessa natureza ou participações em feiras de turismo com o uso dessa tecnologia. Promovendo a estratégia e a tecnologia e abrindo mercado para as empresas produtoras de software.

Tendo em vista o que foi dito anteriormente acerca da pesquisa, a mesma não é conclusiva, nem mesmo tenta aferir conclusões a partir de métodos quantitativos, porém, é exploratória e buscar abrir caminho para que novos estudos e novas pesquisas venham ser desenvolvidas e cada vez mais o objetivo de se encontrarem oportunidades para se utilizar a estratégia mercadológica do marketing sensorial ou marketing de experiências e a tecnologia de realidade virtual para se alcançar uma expansão do conhecimento da tecnologia, consumo da mesma e obviamente receitas através das vendas de softwares de realidade virtual e de produtos que podem ser vendidos através dos mesmos. 


\section{Referências Bibliográficas}

KOTLER, Philip - Administração de Marketing - 10 $10^{\text {a }}$ Edição, $7^{\text {a }}$ reimpressão Tradução Bazán Tecnologia e Lingüística; revisão técnica Arão Sapiro. São Paulo: Prentice Hall, 2000.

Kirner, Claudio; Siscoutto, Robson, Realidade Virtual e Aumentada: Conceitos, Projeto e Aplicações, Pré-Simpósio IX Symposium on Virtual and Augmented Reality, Petrópolis - RJ, 28 de Maio de 2007, página 7

MALHOTRA, N. K. Pesquisa de marketing: uma orientação aplicada. Porto Alegre: Editora Bookman, 2006.

Portal Realidade Virtual, Game Of Thrones - Ascenda a Muralha, Rio de Janeiro, 02 de Junho 2017, <http://www.portalrealidadevirtual.com.br/2017/06/02/game-of-thrones-vrmuralha/>, acesso em: 24 de outubro de 2017

PIMENTA, F. F.; ALMEIDA, B. S. R. "Gameficação do Moodle": uma nova proposta de aprendizagem. In: V SEMINÁRIO INTERNACIONAL DE EDUCAÇÃO A DITÂNCIA. Meios, Atores e Processos. 2013. Resumos... Belo Horizonte: UFMG, 2013. Disponível em: <https://www.ufmg.br/ead/seminario/anais/pdf/Eixo_7.pdf>. Acesso em: 11 mar. 2015.

Schimidt, S. Reage Rio: Volta por Cima da Cidade através do Turismo. O Globo. Rio de Janeiro, 07 de Junho de 2017. Disponível em: <https://oglobo.globo.com/rio/reage-rio-volta-por-cima-da-cidade-atravesdo-turismo-21303085> - Acesso em: 16 de Outubro de 2017;

Souza, Elson, Confira cinco óculos de realidade virtual por menos de $R \$ 100$, Tech Tudo, Rio de Janeiro 22 de fevereiro de 2016, <http://www.techtudo.com.br/noticias/noticia/2016/02/confira-cinco-oculosde-realidade-virtual-por-menos-de-r-100.html>. Acesso em 27 de Outubro de 2017. 


\section{Anexo 1 - Perguntas das Entrevistas com os empresários}

1 - Como surgiu o Projeto Localidades Antigas?

2 - Quais eram os principais objetivos do projeto?

3 - Você acha que o projeto impactou ou poderia impactar o mercado de turismo?

4 - De que forma ou por que não?

5 - Como o aplicativo foi disponibilizado aos clientes?

6 - Como foi a aceitação e o feedback do público que consumiu o aplicativo?

7 - Qual a sua interpretação quanto ao cenário atual da relação entre a RV e o mercado de turismo?

8 - Você enxerga alguma mudança no futuro? 


\section{Anexo 2 - Questionário para consumidores}

1. Você utilizou o aplicativo Localidades Antigas?

2. De forma?
a. Museu
b. Aparelho Pessoal
c. Ambas opções

3. Como foi a experiência?

4. Saberia definir o quê é realidade virtual? O que é? (Caso a resposta seja não ou incorreta, o entrevistador realizará a explicação do que são as tecnologias)

5. Você acredita que uma experiência através da RV possa te influenciar a ponto de criar o desejo de conhecer o Rio de Janeiro? Por quê?

6. Você acredita que essas experiências possam criar algum tipo de vínculo emocional entre você e o Rio de Janeiro? Por quê?

7. Se os produtores desse aplicativo fossem empresas voltadas para o mercado de turismo, os mesmo teriam vantagem competitiva em relação aos concorrentes, de acordo com o seu ponto de vista? Por quê?

8. O que você costuma buscar como base para tomada de decisões em relação as suas viagens?

9. Você já utilizou RV pra tomar alguma decisão na sua vida? Quais ou Por que Não?

10. Se fossem disponibilizados aplicativos que permitissem você "visitar" diversos países, sem que fosse necessário sair do seu sofá. Apenas através da RV, você consumiria? 
11. Sexo
a. Masculino
b. Feminino

12. Idade

13. Estado

14. Cidade

15. Faixa de Renda
a. Mais de 20 salários mínimos
b. 10 a 20 salários mínimos
c. 4 a 10 salários mínimos
d. 2 a 4 salários mínimos
e. Até 2 salários mínimos 